\title{
ON THE APPLICABILITY OF LOW-COST SENSORS FOR Measurements of Aerosol CONCENTRATions
}

\author{
Adnan Masic, Dzevad Bibic \& Boran Pikula
}
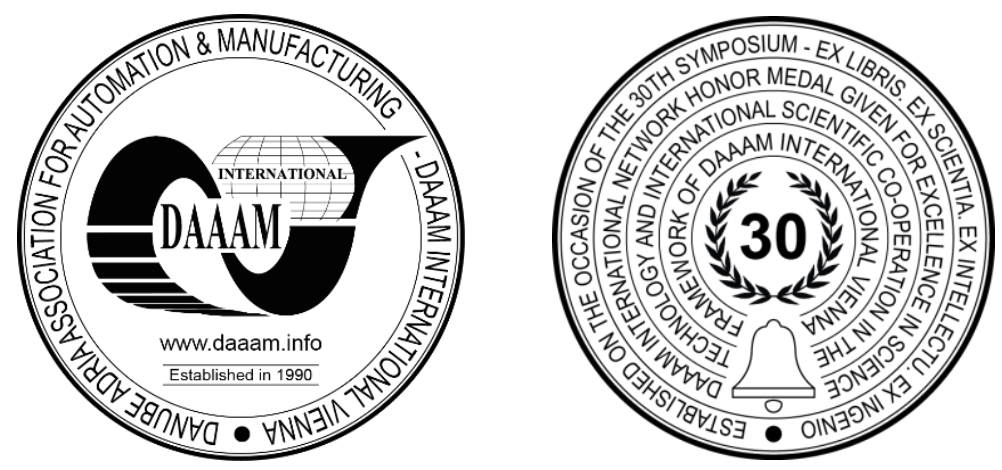

This Publication has to be referred as: Masic, A[dnan]; Bibic, D[zevad] \& Pikula, B[oran] (2019). On the Applicability of Low-cost Sensors for Measurements of Aerosol Concentrations, Proceedings of the 30th DAAAM International Symposium, pp.0452-0456, B. Katalinic (Ed.), Published by DAAAM International, ISBN 978-3-902734-22-8, ISSN 1726-9679, Vienna, Austria

DOI: $10.2507 / 30$ th.daaam.proceedings.060

\begin{abstract}
One of the most important parameters of air pollution, concentration of particulate matter suspended in the air (aerosols), is measured by means of low-cost sensors of latest generation. Such measurements have high resolution in both space and time, but there is a big question about applicability of low-cost sensors for measurements of aerosol concentrations that arise from the complexity of measurement technique, and inevitable errors associated. In this paper we analyze all aspects of applicability of low-cost sensors for long-term measurement campaigns.
\end{abstract}

Keywords: Low-cost sensor; Air pollution; Aerosol concentration; Calibration.

\section{Introduction}

Air pollution is a major issue nowadays: it affects many aspects of our lives, from the health (directly) to the economy (indirectly). There are various components of air pollution, and among all, particles suspended in the air (aerosols) are primary pollutant in most cases [1], [2]. In order to assess the level of air pollution by aerosols, we need to measure their concentrations in the air. But not all aerosols are equally harmful. Particles are classified by their size, and generally, smaller particles are more dangerous. There are many standards and recommendations for particle concentrations, proposed from different organizations. All of them are based on the concentrations of particles smaller than 10 $\mu \mathrm{m}$ (PM10) or $2.5 \mu \mathrm{m}$ (PM2.5). In this study, we will use PM2.5 measurements, since they appear in most studies (PM10 is slowly becoming deprecated for this purpose). The problem is the fact that proper measurement of aerosol concentrations is complex and expensive. Thus, for most polluted areas (poor and developing countries), we don't have much (if any) data.

Recently, new technology has emerged in this field: the low-cost sensors. Table 1 shows main classification of devices for PM2.5 concentration measurements. Most accurate methods are based on gravimetric measurements, but they are expensive and the resolution is very limited in both space and time. Equivalent methods (usually based on the attenuation of beta radiation, BAM) are not as accurate as referent methods, but they are cheaper to run and offer better time resolution. Research grade portable devices, usually based on optical measurement techniques, have even lower cost, better resolution, but they may give inaccurate results, due to the principle of their work. Low-cost sensors are very popular because of their price, size and time resolution (typically $1 \mathrm{~s}$ ) but the question is: can they be used for measurements of PM concentrations at all? We will try to answer this question in the present paper. 


\begin{tabular}{|l|c|c|c|c|}
\hline Method & Reference & Equivalent & Research grade calibrated \\
\hline $\begin{array}{l}\text { Device } \\
\text { example }\end{array}$
\end{tabular}

Table 1. Classification of devices for measurement of aerosol concentrations

There are many papers in which performance of low-cost aerosol sensors is evaluated, for example [3], [4], [5]. However, articles with long campaigns in realistic conditions are very rare. In this paper results of successful long-term comparison of low-cost sensor with professional BAM monitor nearby are presented.

\section{Low-cost sensor of choice}

Taking into account conclusions from our previous studies [5], [6] among all commercially available low-cost sensors, we have selected Plantower PMS5003 sensor. Main reasons for such choice are reliability of the sensors, consistence between units from different batches of sensors, well implemented digital interface and good mean time before failure (MTBF). It is optical based sensor which uses Mie scattering theory for laser scattering on spherical particles to calculate size and concentration of particles in the unit volume of air. This approach, however, inherits several shortcomings for accurate measurement of mass concentrations of aerosols, including:

- $\quad$ assumption that particles are spherical,

- $\quad$ inability to detect particles smaller than $0.3 \mu \mathrm{m}$ in diameter,

- assumption for index of refraction of particles,

- $\quad$ assumption of particles' density.

These parameters may change in the atmosphere over time, which means that there is no correct and permanent factory calibration. Furthermore, high relative humidity in the air may lead to the effect of hygroscopic growth of aerosols [7], [8], which leads to overshoots in measurements at such conditions.

Low-cost sensors are not weather proof, which means that we need to provide proper enclosure. That is not an easy task, because the enclosure must not obstruct sampling of aerosols. Putting PMS5003 sensor into simple box with some openings for the air is not solution, because the sensor has both inlet and outlet on the same side, and such enclosure would lead to inaccurate results due to the cyclone effect. Data acquisition must be performed flawlessly because measurement loses are not acceptable here. All these challenges were previously solved within the framework of our inhouse developed MAQS sensor ecosystem and data acquisition system [9].

\section{Case study}

The city of Sarajevo is affected by aerosol air pollution very much, and it was selected as our case study. Sarajevo is situated in the natural valley, with strong episodes of temperature inversions during winter [10], [11] and very low number of windy days. Results of this study may be relevant for other cities with similar topology of terrain as well. Figure 1 shows the locations of devices for the measurement campaign. We set up two MAQS sensors: MAQS@MEF was located at the Faculty of Mechanical Engineering while MAQS@ETF was installed at the Faculty of Electrical Engineering, University of Sarajevo. The referent device was professional BAM monitor (equivalent method in Table 1) located inside of the complex of US Embassy in Sarajevo (BAM@Embassy). Data collected from the BAM@Embassy are publicly available, but access to the Embassy device was not possible. Strictly speaking, two MAQS sensors were not collocated with BAM, but they were close to each other (200 m from ETF to Embassy and $500 \mathrm{~m}$ from MEF to Embassy), so that it is unlikely that atmosphere can differ significantly at such short distances. 


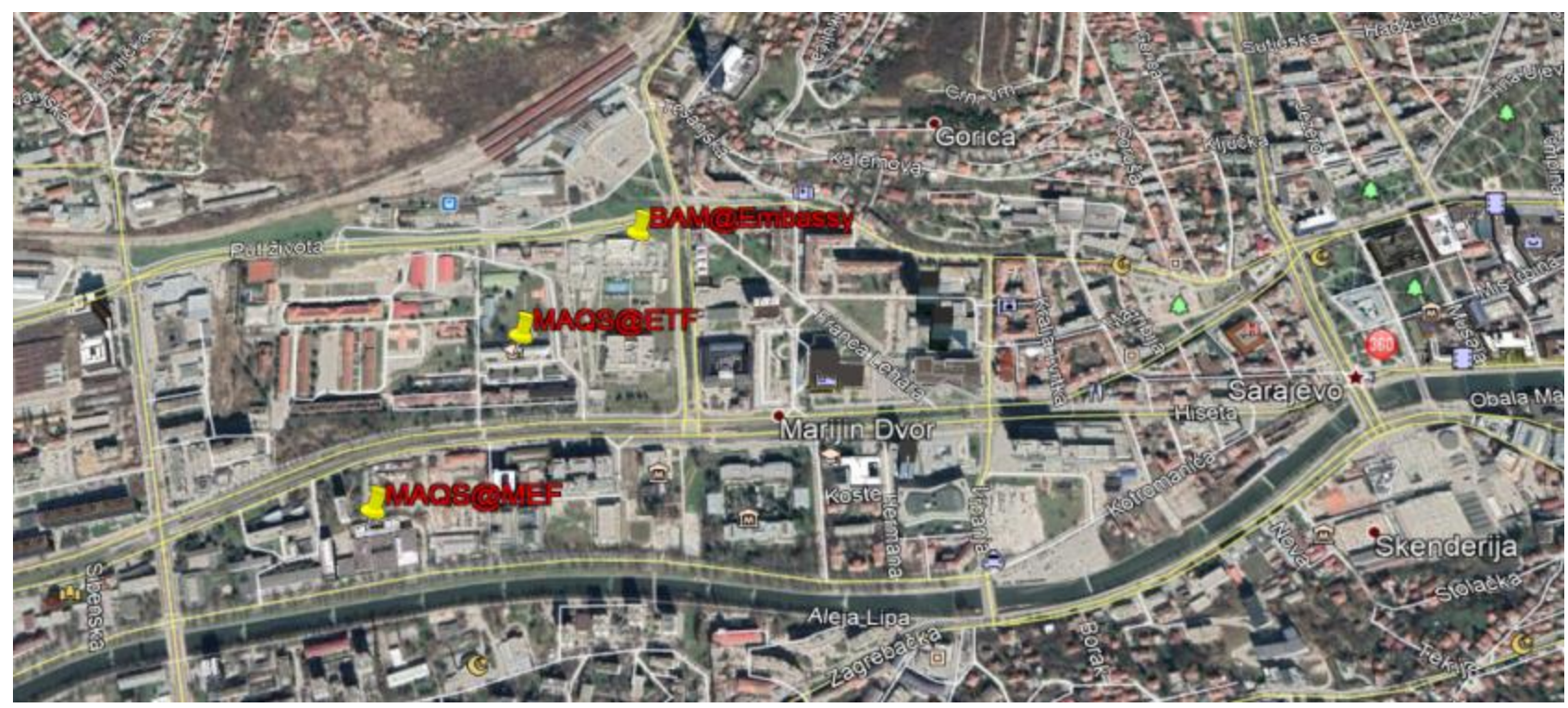

Fig. 1. Location of measurement devices

\section{Results}

Data from Embassy monitor were collected from 23/MAY/2018, MAQS @ MEF started data acquisition on 7/17/2018 and MAQS@ETF started on 2/7/2019. All devices are running continuously as of today, 10/18/2019, which is the last day included in this paper. During this period, many different scenarios were recorded.

Figure 2 shows comparisons of daily average PM2.5 values between two MAQS sensors and BAM@Embassy. The coefficient of determination between MAQS and BAM was sensational: $R^{2}=0.96$ for MAQS@MEF and $R^{2}=0.93$ for MAQS@ETF (please note that MAQS@MEF collected more data than MAQS@ETF, which started after the peak of air pollution during winter 2018/19). The absolute values, however, didn't agree well: MAQS@MEF measured 37\% higher value (on average) than BAM@Embassy, while MAQS@ETF recorded 31\% higher value than BAM (on average).
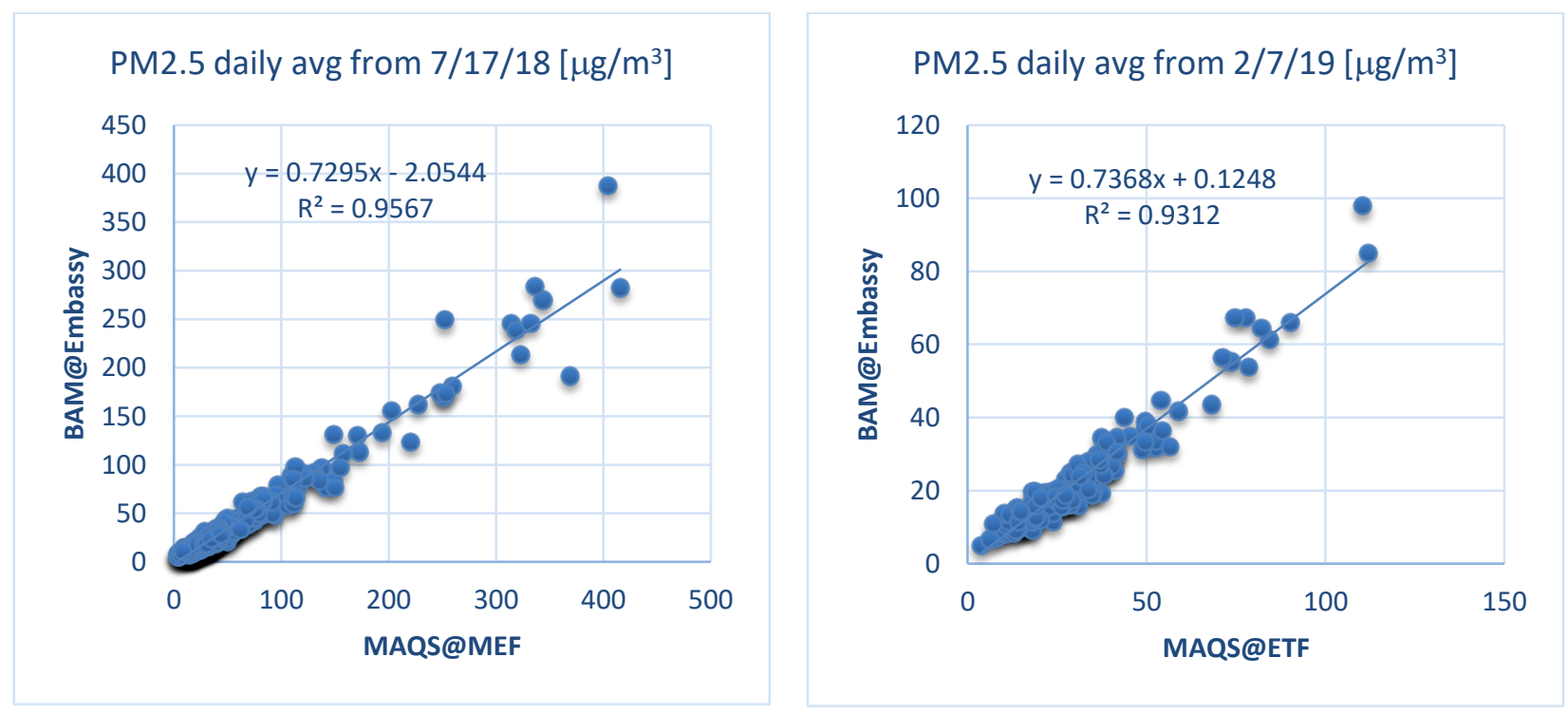

Fig. 2. Daily average values of PM2.5 - comparisons between MAQS sensors and BAM

Figure 3 shows comparisons of hourly average values. Different factors associated to the principle of work of optical aerosol sensor appear as noise in measurements on such timescale. The fact that sensors are not strictly collocated may also play some role here. BAM monitor is not perfectly accurate either, so it is natural, that correlation is weaker in case of hourly average values. But the results are still good: correlation between MAQS sensors and BAM device is high: $R^{2}=$ 0.86 for MAQS@MEF and $R^{2}=0.79$ for MAQS@ETF. Absolute values, again, are overestimated by similar factors as in the case of hourly averages. 


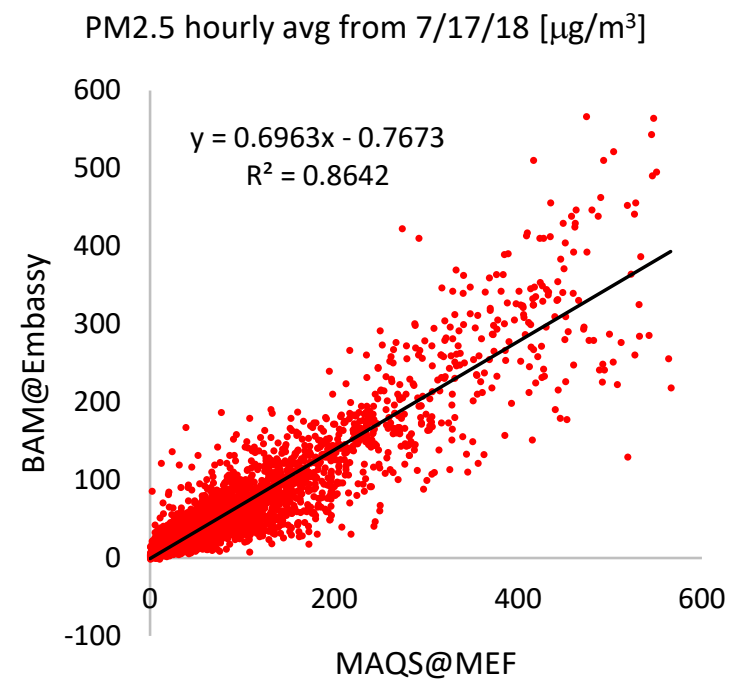

PM2.5 hourly avg from 2/7/19 $\left[\mu \mathrm{g} / \mathrm{m}^{3}\right]$

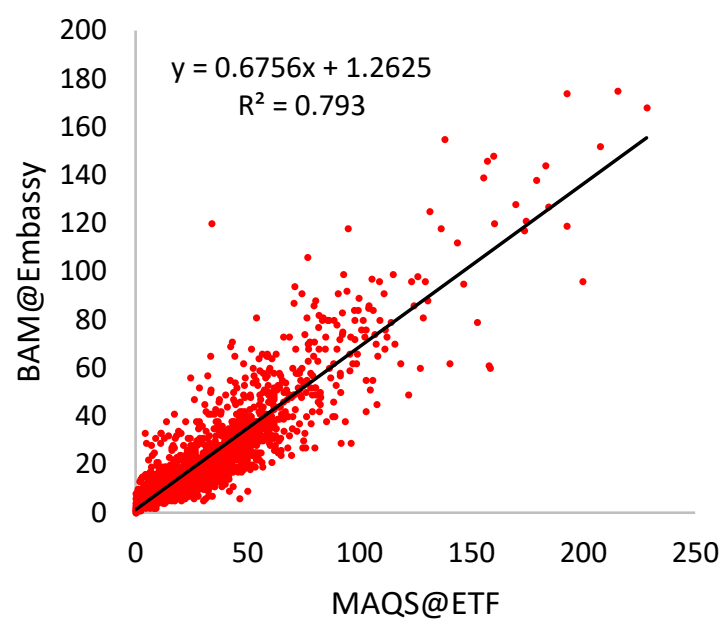

Fig. 3. Hourly average values of PM2.5 - comparisons between MAQS sensors and BAM

Consistency between two MAQS sensors is also important. Figure 4 shows daily and hourly average values for two MAQS sensors. Since the sensors are not collocated (distance between them was about $300 \mathrm{~m}$ ) we don't expect perfect match, but they should be well correlated. Indeed, daily averages had correlation coefficient $R^{2}=0.98$ while hourly averages had $R^{2}=0.96$, which is excellent. Their absolute values were close (well within 10\%).

PM2.5 daily avg from $2 / 7 / 19\left[\mu \mathrm{g} / \mathrm{m}^{3}\right]$

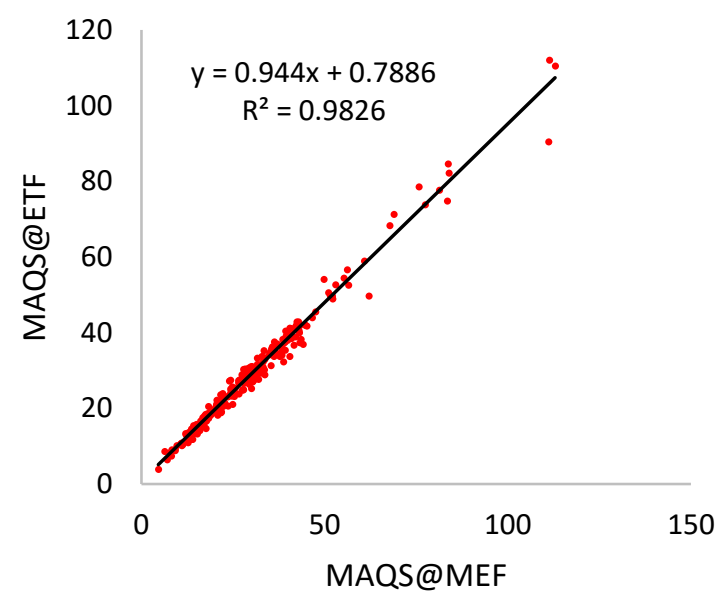

PM2.5 hourly avg from 2/7/19 $\left[\mu \mathrm{g} / \mathrm{m}^{3}\right]$

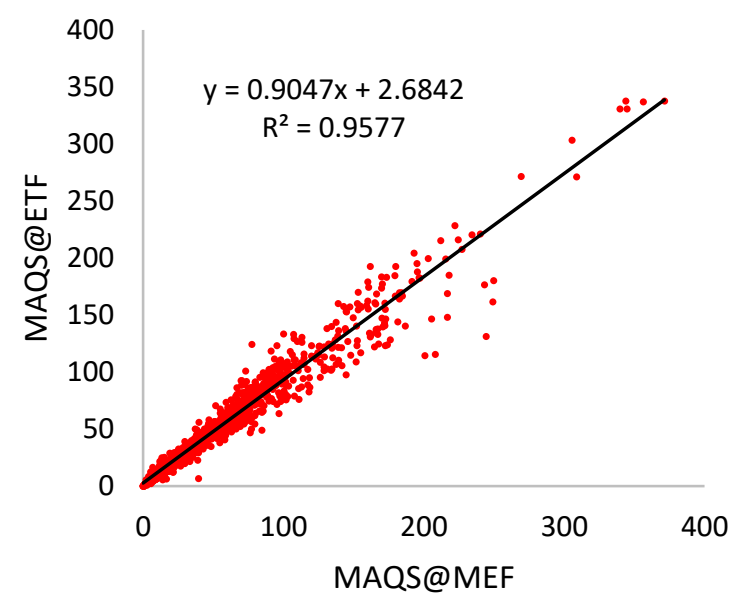

Fig. 4. Daily and hourly average values of PM2.5 - comparisons between MAQS sensors at MEF and ETF

\section{Conclusion}

Low-cost sensors have potential for monitoring of aerosol concentrations: they are affordable and robust (at least those used in this study), they have modern digital interface and can be adapted for outdoor use with proper enclosure. However, low-cost sensors can't be used out-of-the-box for direct measurements of mass concentrations. They must be calibrated, which may be difficult and expensive. If there is any reference or equivalent public station nearby, that is excellent opportunity for comparison and (some kind of) calibration of low-cost sensors. In such cases low-cost sensors could fill the gaps between professional stations, taking into account their time and space resolution.

As suggestion for future work we propose the following activities:

- investigation of humidity influence on low-cost sensors and development of model of correction,

- measurement of concentrations of nanoparticles, which can't be detected with low-cost sensors,

- strict colocation between low-cost sensors and reference monitor,

- using reference (gravimetric) methods for calibration of low-cost sensors under various conditions. 


\section{Acknowledgments}

We would like to thank to Mr. Damir Muslić for his generous contribution to our project by writing core part of the inhouse developed MAQS software.

\section{References}

[1] https://www.epa.gov/pm-pollution/health-and-environmental-effects-particulate-matter-pm, (2019). United States Environmental Protection Agency, Accessed on: 2019-10-18

[2] https://www.who.int/airpollution/data/cities/en, (2018). WHO Global Ambient Air Quality Database (update 2018), Accessed on: 2019-10-18

[3] Crilley, L. R.; Shaw, M.; Pound, R.; Kramer, L. J.; Price, R.; Young, S.; Lewis, A. C. \& Pope F. D.(2018). Evaluation of a Low-cost Optical Particle Counter (Alphasense OPC-N2) for Ambient Air Monitoring. Atmospheric Measurement Techniques, 11, 709-720, 2018, DOI: https://doi.org/10.5194/amt-11-709-2018

[4] Chatzidiakou, L. et al. Characterising low-cost sensors in highly portable platforms to quantify personal exposure in diverse environments. Atmospheric Measurement Techniques, 12, 4643-4657, 2019, DOI: https://doi.org/10.5194/amt-12-4643-2019

[5] Masic, A.; Pikula, B. \& Bibic, D. (2017). Mobile Measurements of Particulate Matter Concentrations in Urban Area, Proceedings of the 28th DAAAM International Symposium, pp.0452-0456, B. Katalinic (Ed.), Published by DAAAM International, ISBN 978-3-902734-11-2, ISSN 1726-9679, Vienna, Austria DOI: 10.2507/28th.daaam.proceedings.063

[6] Masic, A.; Pikula, B.; Bibic, Dz.; Musemic, R. \& Halac, A. (2018). Calibration and Assessment of Low-cost Dust sensors, Proceedings of the 29th DAAAM International Symposium, pp.0523-0528, B. Katalinic (Ed.), Published by DAAAM International, ISBN 978-3-902734-20-4, ISSN 1726-9679, Vienna, Austria, DOI: 10.2507/29th.daaam.proceedings.075

[7] Chen, J. et al. Aerosol hygroscopic growth, contributing factors, and impact on haze events in a severely polluted region in northern China. Atmospheric Chemistry and Physics, 19, 1327-1342, 2019, DOI: https://doi.org/10.5194/acp-19-1327-2019

[8] Jayaratne, R.; Liu, X.; Thai, P.; Dunbabin, M. \& Morawska, L. (2018). The Influence of Humidity on the Performance of a Low-cost Air Particle Mass Sensor and the Effect of Atmospheric Fog. Atmospheric Measurement Techniques, Atmospheric Measurement Techniques, 11, 4883-4890, DOI: https://doi.org/10.5194/amt-11-48832018

[9] Masic, A. (2015). Unmanned Aerial Vehicle as Data Acquisition System. Journal of Trends in the Development of Machinery and Associated Technology. Vol. 19, No. 1, 2015, ISSN 2303-4009 (online), p.p. 181-184.

[10] Masic, A.; Musemic, R. \& Dzaferovic-Masic, E. (2016). Temperature Inversion Measurements in Sarajevo Valley Using Unmanned Aerial Vehicles, Proceedings of the 27th DAAAM International Symposium, pp.0423-0427, B. Katalinic (Ed.), Published by DAAAM International, ISBN 978-3-902734-08-2, ISSN 1726-9679, Vienna, Austria, DOI: 10.2507/27th.daaam.proceedings.062

[11] Masic, A.; Bibic, Dz.; Pikula, B.; Dzaferovic-Masic, E. \& Musemic, R. Experimental study of temperature inversions above urban area using unmanned aerial vehicle. Thermal Science, 2018, DOI: 10.2298/TSCI180227250M 